\title{
Ser e Ter $^{1}$
}

\author{
Maurice Merleau-Ponty ${ }^{2}$
}

Tudo se passa como se o sentido comum e os filósofos tivessem por muito tempo tomado para tipo e ideal do conhecimento humano nossa contemplação dos objetos inanimados, de coisas indiferentes e que não nos toca ou nos afeta. Quando, de minha janela, olho homens que marcham na rua, “... não digo que vejo homens (...); e não obstante, que vejo desta janela, exceto chapéus e capas [mantos] que podem cobrir espectros e homens fingindo se agitarem para saírem. Mas julgo estes homens e assim os compreendo, pelo singular poder de julgar que reside em meu espírito, este que creio ver em meus olhos" (DESCARTES, 1904, p. 25) ${ }^{3}$. Minha percepção de outros homens permite, portanto, analisar dois elementos: aquele é visto propriamente com vestimentas, com contornos corporais, com uma carapaça humana, que Descartes traria, sem dúvida, por um conjunto de sinais coloridos e de traços e, de outra parte, um julgamento pelo qual confiro a esses dados inertes uma significação viva. Voltemos agora, para ao conhecimento do corpo próprio e interroguemos os psicólogos do século XIX. Eles nos disseram que nosso corpo é um conjunto de sensações visuais, táteis, que se distingue de corpos estranhos por muitas características: essa massa de sensações privilegiadas é-me constantemente dadas, ela é acompanhada de impressões afetivas particularmente vivas. E essas características especiais dar-se por um julgamento pelo qual circunscrevo como normal: a contemplação de um conjunto de qualidades, de características esparsas, insignificantes; em face desses dados, desse espetáculo, assenta um sujeito que o interpreta, o compreende, que é, por conseguinte, um puro "poder de julgar", um "Cogito". E como esta análise se aplica muito facilmente ao conhecimento científico, os filósofos se

\footnotetext{
${ }^{1}$ MERLEAU-PONTY, Maurice. Être et Avoir. Section Philosophie et Science. In: La Vie Intellectuelle, Liége: Les Éditions du CERF, $8^{\circ}$ année, nouvelle série, n 1, 1-3, v. 45, pp. 98-109, 15 Octobre. 1936. Tradução de Marquessuel Dantas de Souza.

${ }^{2} \mathrm{O}$ presente texto, consideravelmente, é a segunda publicação intelectual de Merleau-Ponty. Quer dizer, Maurice Merleau-Ponty tornou-se um dos mais renomados pensadores do século XX, e porque não dizer, da história da filosofia. Assim sendo, podemos acrescentar: com apenas 27 anos de idade (1935), o mesmo realizou sua primeira publicação - uma resenha - sobre a obra de Max Scheler (l'Homme du ressentiment); texto este intitulado Christianisme et ressentiment, in: La Vie Intellectuelle, $7^{\circ}$ année, nouvelle série, $\mathrm{n}^{\circ} 2, \mathrm{n}^{\circ} 1-3$, v. 36, pp. 278-306, 10 Juin. 1935. Por vezes, aqui traduzimos sua segunda produção intelectual publicada no mesmo periódico, conquanto, em 1936, quando Merleau-Ponty contava com 28 anos de idade. - Resenha da obra de Gabriel Marcel Être et Avoir. Paris: Fernand Aubier, Éditions Montaine, 1935. 357p. (Collection Philosophie de l'Esprit). - Todos os grifos no corpo do texto são conforme o original. (N. T.).

${ }^{3}$ DESCARTES, René. $2^{\mathrm{a}}$ meditação, A. T., IX. In: Oeuvres de Descartes, publiées par Charles Adam et Paul Tannery, sous les auspices du Ministère de l'Instruction Publique. Paris: L. Cerf, 1897-1913. 13 v.
} 
asseguram que todo conhecimento é um diálogo entre um "sujeito" e um "objeto" no sentido acima definido.

Contra estas reduções e contra a teoria do conhecimento que os envolvem, os primeiros ensaios de Gabriel Marcel protestam. Os homens que, por um olhar distraído, olho passar na rua, talvez não me pareçam mais que manequins vestidos; mas é também por uma espécie de "especulação enfraquecida"4; tomamos aqui por modelo da percepção de outrem um conhecimento distraído [desatento], onde, com efeito, não percebo homens, mas formas humanas que se movem vagamente. Ao contrário, o homem que está presente, este a quem me endereço e que está verdadeiramente diante de mim é uma segunda pessoa, esta não é redutível a um conjunto de características, cujo pacificamente farei a "descoberta". Mas, mesmo por considerar meu corpo tal qual se apresenta a mim, distinguimos o conhecimento que tenho por não deixar conduzir ao tipo pretendido normal cujo desenhamos mais alto o esquema. Isso não acrescenta a uma massa de sensações visuais e táteis de impressões afetivas, de "sensações duplas", como se diz, ou mesmo de julgamentos e todo um saber que lhe reportará deste feito singular o qual meu corpo é precisamente meu corpo. Ele não me parece como um objeto, como um conjunto de qualidades e de características que se trataria de coordenar e de compreender; as relações que tenho com ele não são aquelas do cogito e do cogitatum, do "sujeito epistemológico" e do objeto. Faço causa comum com ele, e, de certa maneira, eu sou o meu corpo ${ }^{5}$. Dele para mim não posso dizer que há uma relação, porque este termo designa o comportamento de um objeto a respeito de um objeto. Ele atua de preferência por uma presença, por uma aderência, por uma intimidade. Mas da mesma maneira, na medida aonde creio verdadeiramente nos objetos, onde apreendo antes suas "características", sua fisionomia, sua presença antes que sua essência, ele torna-se alguma coisa como o prolongamento de meu corpo. Não é sobre meu corpo tal como o sinto sobre os objetos, tal como os homens o assegura vivo entre eles que os filósofos fizeram levar suas análises. Eles estão estabelecidos numa "atitude espetacular" (MARCEL, 1935, p. 25) ${ }^{6}$ que desposa o objeto de seu aspecto humano, de suas ações sobre nós, ao mesmo tempo em que eles liberam o sujeito de situações tais que a esperança, o desespero, a promessa, a invocação, onde é tão esforçada em direção ao outro que se torna inseparável. Para entender o "Eu" como

\footnotetext{
${ }^{4}$ Scheler.

${ }^{5}$ É interessante chamar atenção do leitor para esta última passagem: eи sou o теи corpo. Uma vez que este raciocínio estará presente na obra Fenomenologia da Percepção de 1945. Lembrando que o presente escrito de Maurice Jean Jacques Merleau-Ponty é de 1936. (N. T.).

${ }^{6}$ MARCEL, Gabriel. Etre et Avoir. Paris: Aubier, Éditions Montaigne, $1935.357 \mathrm{p}$.

\begin{tabular}{|l|l|l|l|l|}
\hline Ronista Qialeatus & Ano 3 & n. 8 & Janeiro - Agosto 2016 & p. 146-153 \\
\hline
\end{tabular}
}


absoluto - sem fixá-lo -, convém que o filósofo trate ele mesmo como um objeto, que adote o outro lado ele próprio desta atitude espetacular que aprendemos por abordar para tomar em face dos outros. Neste sentido, o Cogito está bem longe de ser a primeira verdade, a condição de toda certeza válida. A raiz da ingênua afirmação é antes, a consciência de meu corpo que subentende talvez toda a afirmação da existência que toca as coisas. "A encarnação, dado central da metafísica, dar-se a partir do qual um fato é possível (esta não é a verdade do Cogito)" $"$.

Os mais recentes trabalhos de Gabriel Marcel permitem precisar a significação filosófica destas notas. Não é somente distinguir, para o lado do mundo físico e do universo da ciência, das regiões - deste corpo próprio; de tu - que, com efeito, não permitiriam anexar. Percebemos, cada vez melhor, que as análises do corpo próprio e do tu foram os primeiros ensaios de um método geral, os primeiros exemplos de um tipo novo de conhecimento. Parece que a fenomenologia aqui tem fornecido a Gabriel Marcel não verdades de fato, mas um meio de explicitar e de justificar o que implicam suas primeiras reflexões. Por isso mesmo quando elas precisam numa oposição da existência e da objetividade ${ }^{8}$, um leitor desatento [distraído] poderia sustentar que apesar de tudo pode-se distinguir dois "conteúdos de pensamento", acrescentando [adicionando] só um capítulo à psicologia do conhecimento. A fenomenologia, na medida em que interdita [proíbe] evocar por trás do objeto atual ou virtual de nossos pensamentos das coisas que lhe poderia não assemelhar-se em nada, confere imediatamente um valor irrecusável às distinções estabelecidas entre “conteúdos de pensamentos”. É neste sentido que Gabriel Marcel pode adotar um "ponto de vista transcendental" ou "fenomenológico"10. Existência e objetividade podem, portanto, aparecer mais como dois fenômenos no sentido restrito da palavra; estes são, doravante, duas regiões do ser. Ao mesmo tempo em que ele aproxima o ser do objeto, por esta simples razão o único ser do qual podemos falar é este que conhecemos que fosse de uma maneira inadequada, um método fenomenológico liga o sujeito ao ser, definindo como uma tensão ou intenção orientada na direção de um termo. Desde então se abre um campo de pesquisas que transborda o corpo próprio e o tu para entender-se em geral a todos os "empenhos" da alma. Tomemos por tema

\footnotetext{
${ }^{7}$ Etre et Avoir, pp. 11 e 12. - Este parágrafo mostra o contraste no pensamento de Merleau-Ponty em relação ao pensamento de Descartes. Algo que se fará presente na Fenomenologia da Percepção de 1945. Acréscimo do tradutor.

${ }^{8}$ Ver o artigo "Existência e Objetividade", reproduzido no Jornal Metafísico (Journal Métaphysique).

${ }^{9}$ Etre et Avoir, p. 157.

${ }^{10}$ Ibid. p. 229.
}

\begin{tabular}{|l|l|l|l|l|}
\hline Revista Dialectus & Ano 3 & n. 8 & Janeiro - Agosto 2016 & p. 146-153 \\
\hline
\end{tabular}


de análise o homem que percebe que pensa, que quer, que espera, ama, adora, invocado tal que é visado ou ao menos pressente nestes mesmos atos. Com Ser e Ter a filosofia de Gabriel Marcel está, por assim dizer, amplificada: ela tende a tornar-se uma compreensão da vida, do conjunto das situações vividas pelo homem, com sua ambiência própria. Cada vez mais o centro de perspectiva se distancia do corpo e se aproxima da alma. Pois se meu corpo é mais que um objeto que eu possuiria, não posso dizer mais do que sei de mim mesmo: ele é "a fronteira deste que sou e deste que tenho", no limite do ser e do ter. O fato central da metafísica é sem dúvida, como dissemos a pouco - a presença e separação de meu corpo: estar de preferência na nova obra de Gabriel Marcel a presença e a separação de minha vida, a aderência de minha vida para mim mesmo e ao mesmo tempo meu poder de sacrificar, minha recusa me confronta com ela.

Trata-se aqui de pensar que a maioria das filosofias é tida por produto sem valor. Visto que não estamos "equipados" para pensar a existência, e todo o trabalho resta por fazer. É surpreendente ver como os filósofos foram prudentes ou receosos quando se tratava de forjar designações novas pelos aspectos da existência aos quais eles mais mantinham. Experimentamos, por exemplo, em analisar a existência da alma cristã com ajuda de noções aristotélicas, esta que é como um paradoxo. Uma vez que no cristianismo é essencial à vida do ser um problema para as almas poderem ser perdidas ou salvas. Entre esta alma e a alma como "forma do corpo" de Aristóteles, não ver-se como pode se fazer a junção. "A forma é essencialmente salva, ela mesma não pode ser ameaçada"11. Acontece que ela se deixa transbordar, por assim dizer, pela matéria, mas ela própria permanece intacta e se ausenta somente para consentir lugar à causalidade material. Logo, é um fato que pode ter na alma uma "vontade de se perder" ". E mesmo a saudação da alma, se ela é a "forma do corpo", não é mais que a conservação de uma hierarquia natural, o funcionamento normal de um mecanismo metafísico. Como pretender que a noção cristã de saudação reduz-se a esta boa santidade, a vida religiosa a esta higiene? Teremos, portanto, de transformar nossas categorias. Deveríamos também nos habituar a considerar a "prova" como um modo de segundo pensamento. "A prova não pode nos confirmar o que em realidade nos foi dado em

\footnotetext{
${ }^{11} \hat{E}$ tre et Avoir, p. 32.

${ }^{12}$ Etre et Avoir, p. 32. É verdade que as formas que estão na matéria podem se corromper. Mas elas passam então do ser ao não-ser, e não é a rigor a mesma forma que se corrompe, não é ela que se perde. O problema é um dos quais a teologia está muito conscientemente atada ou unida, em seu esforço para pensar a Revelação com auxílio de noções elaboradas pela filosofia grega.
}

\begin{tabular}{|l|l|l|l|l|}
\hline Revista Dialectus & Ano 3 & n. 8 & Janeiro - Agosto 2016 & p. 146-153 \\
\hline
\end{tabular}


outro lugar"" "Ela consiste em reconduzir no nível do pensamento discursivo um ato diferente" ${ }^{\prime 4}$. Ela não fita inteiramente o que é feito para provar, ela desenha [representa] o esquema ou prepara a passagem [o caminho] de um ato cuja mesma não é exatamente o equivalente. Quando se trata do que existe mais verdadeiramente, a reflexão consiste menos em buscar a natureza para explicitar as razões pelos quais não há aí a natureza por conhecer. Ela marca as fronteiras que separam os problemas, ou que determina um desconhecido por suas relações com os termos conhecidos e os mistérios, onde o enigma (por exemplo, o sentido do sofrimento) não pode ser resolvido por uma combinação de noções, mas só por atos de sacrifícios ou de desespero. Está claro que desta maneira o filósofo prepara um caminho para a esperança; mas não demonstra, não prova, somente desenha uma experiência insubstituível, mostrando porque ela é. Tão é a prova segunda, a certeza não se articula necessariamente em julgamentos explícitos e em noções circunscritas. E é porque "não sou eu mesmo este que creio" 15 . Em igualdade de Fé, poderíamos mesmo falar, senão de prova, ao menos de verificação? Verificar, é sempre apelação a um observador mais exato ou menos prevenido (que este observador seja nós mesmos ou um outro) para eliminar esta nossa primeira observação que poderíamos ter de pessoal. Quer dizer, tal operação perde toda significação desde que se trate de ver este que, por hipótese, é inacessível a um olhar indiferente e não se revela ao preço de um compromisso pessoal. Perguntar aqui por uma "experiência retificada" seria postular que a verdade é o que pode ser verificado por todos ${ }^{16}$. A certeza se confunde, portanto, com uma espécie de essência de "intuição eficiente"17. "Não seria a essência deste que é ontológico de não poder ser atestado?" ${ }^{18}$. Há uma maneira de confirmar esse atestado: é de mostrar que, por essência, ela vale melhor que toda confirmação.

As análises da promessa, do compromisso, do ter, longe de descrever alguns "estados de consciência", alcançado por um organismo que repousa em si mesmo sobre o mundo físico, nos introduzem em um mundo novo que compreende o outro e não é compreendido. Todas as perspectivas são invertidas. A tentação e a fidelidade não são mais que "acontecimentos interiores" que seriam seus assentos numa consciência fechada no espaço e no tempo; mas

\footnotetext{
${ }^{13}$ Etre et Avoir, p. 176.

${ }^{14}$ Ibid. p. 141.

${ }^{15}$ Ibid. p. 177.

${ }^{16}$ Etre et Avoir, p. 308.

${ }^{17}$ Ibid. p. 177.

${ }^{18}$ Ibid. p. 143.
}

\begin{tabular}{|l|l|l|l|l|}
\hline Qevista Dialectus & Ano 3 & n. 8 & Janeiro - Agosto 2016 & p. 146-153 \\
\hline
\end{tabular}


inversamente o espaço e o tempo são as "formas da tentação" "19 de caso-limite de carência, como o ser é o "lugar das fidelidades", o caso-limite da presença; e esta presença e esta carência não devem ser pensados como modos da proximidade e da distância espaciais e temporais: ao contrário, ele faz derivar estes daqueles. A teoria do tempo, em particular será, portanto para recomeçar. De certo modo, um amigo perdido está presente em meu pensamento vivo mais verdadeiramente que um "vivo" que não amo ${ }^{20}$. Pensa-se habitualmente o tempo pela analogia de um pedaço de lenha que se consume: o passado é esta cinza que nenhum ardor animará; ele é alguma coisa ao qual não podemos alterar coisa alguma. Mas se penso em um amigo já falecido, é necessário que já esteja. Se me está presente, quem espera, por assim dizer, que existo? Qual prova ou qual critério, pergunto eu, já que este gênero de existência não comporta por definição nenhuma prova e nenhum critério? "Não há sedimentação histórica" 21 e nada é irrevogável, podemos atuar não somente sobre o presente, mas também sobre o passado. Podemos ainda agir sobre o futuro, e isto que o prova, é o empenho [o compromisso, a promessa]. - Prometo a um amigo doente de voltar a vê-lo. "No momento em que me comprometo ou presumo arbitrariamente uma invariabilidade do meu sentir do qual não está realmente em meu poder em instituir, ou aceitar antes de ter concluído por um dado momento um ato que não refletirá de modo algum minhas disposições interiores quando cumprirei. No primeiro caso, minto para comigo mesmo; no segundo caso, é por outrem que antes consinto em mentir" ${ }^{22}$. Entretanto, nenhuma análise me fará descobrir, na promessa, que é uma verdadeira promessa; uma dessas duas mensagens envolvidas. E como aparência e realidade se confundem aqui, essas duas mensagens não são. O que é, portanto, a promessa, senão o ato de um ego que não se confunde com os estados psíquicos cujo sou a testemunha ou o proprietário, com exceção de uma manifestação de meu ser no qual meu devir não tem o poder de anular? Em um sentido, mesmo que todo o passado venha a ser presente desde o instante que me é presente, toda promessa é como ordem desde o instante que ela é verdadeira [sincera]. Se amanhã eu não estiver mais ao alcance do mesmo élan entre meu amigo doente, esta traição não constitui que minha promessa inexistiria e nem continue por existir em meu ser senão em minha vida. Tal é o esforço pelo qual Gabriel Marcel libera em sua pureza os atos espirituais, para o quais os opôs às falsificações do qual

\footnotetext{
${ }^{19}$ Ibid. p. 30.

${ }^{20}$ Nossa resenha sublinha isto que há de paradoxal e insustentável nesta visão. Mas Gabriel Marcel o sublinha todo o primeiro e objeta em si que o vivo que não amo não vive para mim, mas vive para si, este que me parece, reconduz a distinção do conteúdo de pensamento e do real, e obriga a um certo realismo do tempo.

${ }^{21} \hat{E}$ tre et Avoir, p. 70.

${ }^{22}$ Ibid.
}

\begin{tabular}{|l|l|l|l|l|}
\hline Q Rovista Dialectus & Ano 3 & n. 8 & Janeiro - Agosto 2016 & p. 146-153 \\
\hline
\end{tabular}


seu semelhante ${ }^{23}$ remonta sem cessar do domínio do ter ao domínio do ser. É este movimento entre o ter e o ser, aquele meio termo que definem a condição humana.

A objeção que se apresenta ao espírito na presença de tal filosofia, é que lhe falta alguma espécie de uma força obrigatória. "Há uma coisa que se chama viver, há outra coisa que se chama existir: eu escolhi por existir" ${ }^{\text {24 }}$. Está aí uma opção e não seria de outra forma. Mas deve-se perguntar se a reflexão não pode controlar o mais próximo esta opção. Caracterizar, descobrir critérios que resistem as dúvidas, tomar os inventários dos objetos de pensamento, essas operações favoritas dos filósofos estão longe de definir a mesma inteligência. Trata-se de certo uso da inteligência, nada mais - Gabriel Marcel o sabe bem -, e jamais sua filosofia se torna um som "anti-intelectualista". Nada é mais conforme a razão do que esta renúncia de certa razão. Mas a inteligência, uma vez "reequipada", não pode servir para inverter os obstáculos que se opõem a intuição decisiva? “... Não podemos proceder aqui, chamando como Karl Jaspers em sua Filosofia da Existência; se, como tive a ocasião de constatar, que certas consciências respondem (...) é que há um verdadeiro caminho. Mas (...) este caminho não pode ser revelado por amor, não é visível por si só” ${ }^{25}$. Aqui, o autor como pessoa sente melhor que o lugar dado à filosofia propriamente dita é estreito. E desde então, se "tenho visto", é um argumento último; esta filosofia não autoriza qualquer pseudointuição? Como distinguimos a intuição autêntica da ilusão? Questão que o autor descarta, pois perguntamos sobre um critério para este que, não sendo da ordem "dele", não seria por comportar-se. Contudo, sabemos distinguir, por exemplo, o lirismo verdadeiro do delírio; e, quando chega que as palavras de uma criança ou de um insano se torna o som da poesia autêntica, nossa surpresa é esta espécie de choque que sentimos [provamos], e assim advertimos o suficiente [o bastante] que há dois registros absolutamente diferentes. Somos, portanto, convidados a esclarecer essa distinção imediata desta que está acima da razão e desta que está abaixo dela. Se toda intuição é suficiente, se não havia nenhum caminho não dialético que conduzisse ao conhecimento inadequado a um caminho mais adequado, como cada ser fechado em suas intuições imperfeitas sentiriam a necessidade de ir mais longe, de passar da realidade? As existências as quais conhecemos não são elas mesmas uma certa estrutura, não nos apresentam aspectos parciais e sutis como tais - dos lados - cujo cada um é um convite para irmos mais longe? Gabriel Marcel o crê sem dúvida, uma vez que, qualquer

\footnotetext{
${ }^{23}$ Ver em particular as análises da esperança.

${ }^{24}$ Etre et Avoir, p. 162.

${ }^{25}$ Posição e aproximação concreta do mistério ontológico, p. 208.
}

\begin{tabular}{|l|l|l|l|l|}
\hline Qevista Q Dialectus & Ano 3 & n. 8 & Janeiro - Agosto 2016 & p. 146-153 \\
\hline
\end{tabular}


parte em sua obra, mantém a possibilidade de uma dialética e fala de um método "hiperfenomenológico" 26. - Não estamos lidando com uma filosofia concluída. Chegamos a apresentá-la como tese esta que, na obra, é "proposição”. Nada será mais temerário e também mais justo que opor as "refutações" às sugestões.

${ }^{26}$ Etre et Avoir, pp. 206-207. 